\title{
Strategy for sneaking into a host's home: The cuckoo wasp Omalus biaccinctus (Hymenoptera: Chrysididae) inserts its eggs into living aphids that are the prey of its host
}

\author{
PATRICK WINTERHAGEN \\ University of Hohenheim, Institute of Crop Science (340f), Emil-Wolff-Str. 25, 70593 Stuttgart, Germany; \\ e-mail: p.winterhagen@uni-hohenheim.de
}

Key words. Hymenoptera, Chrysididae, Crabronidae, Omalus biaccinctus, cuckoo wasp, aphid, cleptoparasite, cytochrome oxidase I, insect parasitoid strategy, oviposition

\begin{abstract}
Parasitic Hymenoptera usually need to have direct access to their host or its offspring or to be able to enter and place their offspring in a nest of their host, where their progeny develop at the expense of the host. In the case of the cleptoparasitic cuckoo wasps (Chrysididae) their main target is the nest of the host and they have various strategies for locating and entering their host's brood cells for ovipositing. The chrysidid Omalus biaccinctus (Buysson, 1893), a parasitoid of aphid hunting crabronid wasps, was observed apparently inserting its eggs into living aphids at the hunting site of their host and the presence of the parasitoid's egg and DNA in aphids after oviposition was confirmed. It is concluded that O. biaccinctus "hitch-hikes" into a host's brood cell concealed in the aphid prey collected by the host wasp and the adult parasites do not need to enter the nest of their host in order to lay their eggs.
\end{abstract}

\section{INTRODUCTION}

Parasitism among insects is prevalent and mainly described for the orders Diptera, Coleoptera, and Hymenoptera (Eggleton \& Belshaw, 1992; Pennacchio \& Strand, 2006). Insect parasitoids can play a crucial role in pest control in agriculture, e.g. the control of aphid populations by aphidiidae, but hyperparasitism can reduce their effect (Mackauer \& Völkl, 1993). Among other topics, research on parasitic Hymenoptera includes investigations on how those that parasitize the brood in the nests of their hosts are able to access these nests (Rosenheim, 1987; Pennacchio \& Strand, 2006; Collett, 2008; van Nouhuys \& Kaartinen, 2008). Parasitic wasps oviposit directly onto the surface or into the body of their hosts, or nearby their hosts, and the parasite develops as exo-, endo- or cleptoparasite (Pennachio \& Strand, 2006). Many sophisticated insect host-parasite relationships have evolved, including strategies that enable parasites to overcome even the host's defense (Strohm et al., 2001, 2008; Pennacchio \& Strand, 2006).

Cleptoparasitic cuckoo wasps (Chrysididae) generally deposit their eggs in the brood cell of their host and their larvae feast on the host larvae and/or the provisions stocked in the brood cell (Rosenheim, 1987; Strohm et al., 2008). These cuckoo wasps have evolved different means of locating and accessing the nests of their hosts (Kurczewski, 1967; Rosenheim, 1987; Strohm et al., 2008). Usually the adults of these chrysidid (clepto)parasitoids have to identify and enter the host nest, which involves a possibility of being recognized and disturbed by the host (Kurczewski, 1967; Rosenheim, 1987; Strohm et al., 2008).

A different strategy is described by Carrillo \& Caltagirone (1970), who report that the chrysidid Pseudolopyga taylori lays its eggs in the lygaeid bug Nysius raphanus (Lygaeidae), which is the prey of the host wasp, Solierella spp. (Crabronidae). The host wasp also collected bugs containing eggs of the chrysidid to provision its brood cells, and the parasitic chrysidid is thus able to enter the nest of its host. A similar strategy is suggested for the European chrysidid Holopyga generosa which lays eggs in the bug Palomena prasina (Pentatomidae) (Veenendaal, 2012).
It has been also speculated that some European chrysidids belonging to the genera Pseudomalus and Holopyga, which parasitize aphid-hunting crabronid wasps, may use a similar strategy as some individuals have been observed apparently ovipositing in aphids (http://forum.hymis.de/viewtopic.php? $\mathrm{f}=14 \& \mathrm{t}=5073$ ). The present study provides evidence that the chrysidid Omalus biaccinctus (Buysson, 1893), which is a cleptoparasite of aphidhunting crabronid wasps, oviposits in living aphids at the host wasps' hunting site.

\section{MATERIAL AND METHODS}

\section{Observation of insect behavior}

The chrysidid Omalus biaccinctus and crabronid Passaloecus spp. were frequently observed on potted Capsicum plants infested with Macrosiphum euphorbiae and Myzus persicae nicotianae (Aphididae) from June to August 2014 on hot and sunny afternoons in Baden-Württemberg, Germany. The cuckoo wasps were captured and oviposition on aphids was monitored under controlled conditions. Detached Capsicum leaves with aphids of various developmental stages were offered and after oviposition, the aphids were collected for further analysis. The body surface and body contents of the aphids after dissection were examined for the presence of parasitoid eggs using a stereo microscope.

\section{DNA isolation and PCR analysis}

DNA from aphids and $O$. biaccinctus was isolated using micropestles and the Epicentre DNA extraction kit No. MPP92100 following the manufacturer's recommendations. The DNA sample of $O$. biaccinctus was used for amplification of a cytochrome oxidase I (COI) gene fragment using gradient PCR and different degenerate/general COI primers: S1541 (Simon et al., 1994), C2-N-3661 and C1-N-2191 (Kelley et al., 2000), and the primers chrCOI-F (5'-TAT CCT CGA ATA AAT AAT ATA AGA TTT TGA-3') and chrCOI-R (5'-AAA TCA AAA TAA ATG YTG ATA YAA-3') designed for chrysidid COI sequences. The PCR cycling conditions were: initial denaturation for $10 \mathrm{~min}$ at $95^{\circ} \mathrm{C}$, followed by 35 cycles with denaturation for $30 \mathrm{~s}$ at $95^{\circ} \mathrm{C}$, an- 
nealing for $20 \mathrm{~s}$ at $48^{\circ} \mathrm{C}$ to $52^{\circ} \mathrm{C}$, extension for $40 \mathrm{~s}$ at $72^{\circ} \mathrm{C}$, and a final extension step of $5 \mathrm{~min}$ at $72^{\circ} \mathrm{C}$. Amplification products were visualized for evaluation via agarose gel electrophoresis and using ethidium bromide staining and UV illumination. Obtained PCR products were cloned into the pGEM T-easy vector (Promega) and amplified in E. coli TOP10 cells (Life Technology) for subsequent plasmid preparation and sequencing at GATC Biotech AG. The resulting $O$. biaccinctus $\mathrm{COI}(\mathrm{ObCOI})$ sequence was analyzed by BLAST search at NCBI, by sequence alignment and neighbour joining phylogeny (bootstrap $=1000$ ) using ClustalW and MEGA4 software, respectively (Larkin et al., 2007; Tamura et al., 2007). After sequence verification primers targeting $\mathrm{ObCOI}$ were designed (ObCOI-F: 5'-TTA ATT TTA AGA GGG TTT ATA GGA-3', ObCOI-R: 5'-TGT TAA TAA TAT TGT AAT AGC C-3') and used for specific and highly sensitive nested PCR. Cycling conditions were as above, but initial denaturation was $3 \mathrm{~min}$ and annealing was done at $50^{\circ} \mathrm{C}$, respectively. Resulting amplicons were cloned and specificity was verified by sequencing.

\section{RESULTS AND DISCUSSION}

\section{Observation and verification of oviposition}

For cuckoo wasps of the genus Omalus (Chrysididae) there is so far no evidence that they look for the nesting sites of their host so there is a gap in our knowledge of how these species find and parasitize their hosts. The data presented suggests that they circumvent the need to identify and actively access the nests of their hosts. It was repeatedly noticed that individuals of $O$. biaccinctus were highly active on Capsicum leaves infested with aphids and they frequently appeared to oviposit in or on the aphids as they touched aphids with their ovipositor, although living aphids are not the host of this parasitoid. The interpretation of this behaviour, which was recently also observed in other related species, was uncertain; the chrysidids could also stimulate aphids to exude honeydew as food (http://forum.hymis.de/viewtopic. php?f=14\&t=5073; http://bugguide.net/node/view/109964; webpage access: 2015/28/01).

In this study, monitoring several individuals of $O$. biaccinctus revealed that they ignored honeydew exuded by the aphids. These cuckoo wasps will occasionally completely eat aphids without touching them with the ovipositor. However, the aphids selected for oviposition, after being examined with the antennae, are gripped by the wasp's forelegs and the ovipositor is pushed against the ventral side of the aphid (Fig. 1A). It was further noticed that within a group of aphids present on a single leaf only few (two to three) were handled in this way before the wasp left to search for aphid colonies on other leaves. While cuckoo wasps were busy with apparently laying eggs in aphids, a crabronid wasp of the genus Passaloecus (Crabronidae) was frequently seen searching for aphids nearby. The crabronid wasp (Fig. 1B) was collecting aphids from the same plant supposedly to stock its nest with prey for its offspring. Passaloecus is known to provision its nest with several aphids for each larva, and also to be parasitized by species of Omalus, which adversely affects the host's survival rate (Corbet \& Backhouse, 1975; Fricke, 1992; Veenendaal, 2011). When the crabronid wasp ceased foraging and left the hunting site the cuckoo wasps left the area, too, but returned as soon as the crabronid resumed foraging there for prey. Based on this field observation it is assumed that cuckoo wasps follow their hosts to the sites where they forage for aphids.

The observations described above inspired me to catch cuckoo wasps that were busy with ovipositing to monitor their behavior in captivity. The captured $O$. biaccinctus individuals immediately approached the offered aphids feeding on a detached leaf, touched and examined an individual using its antennae and then
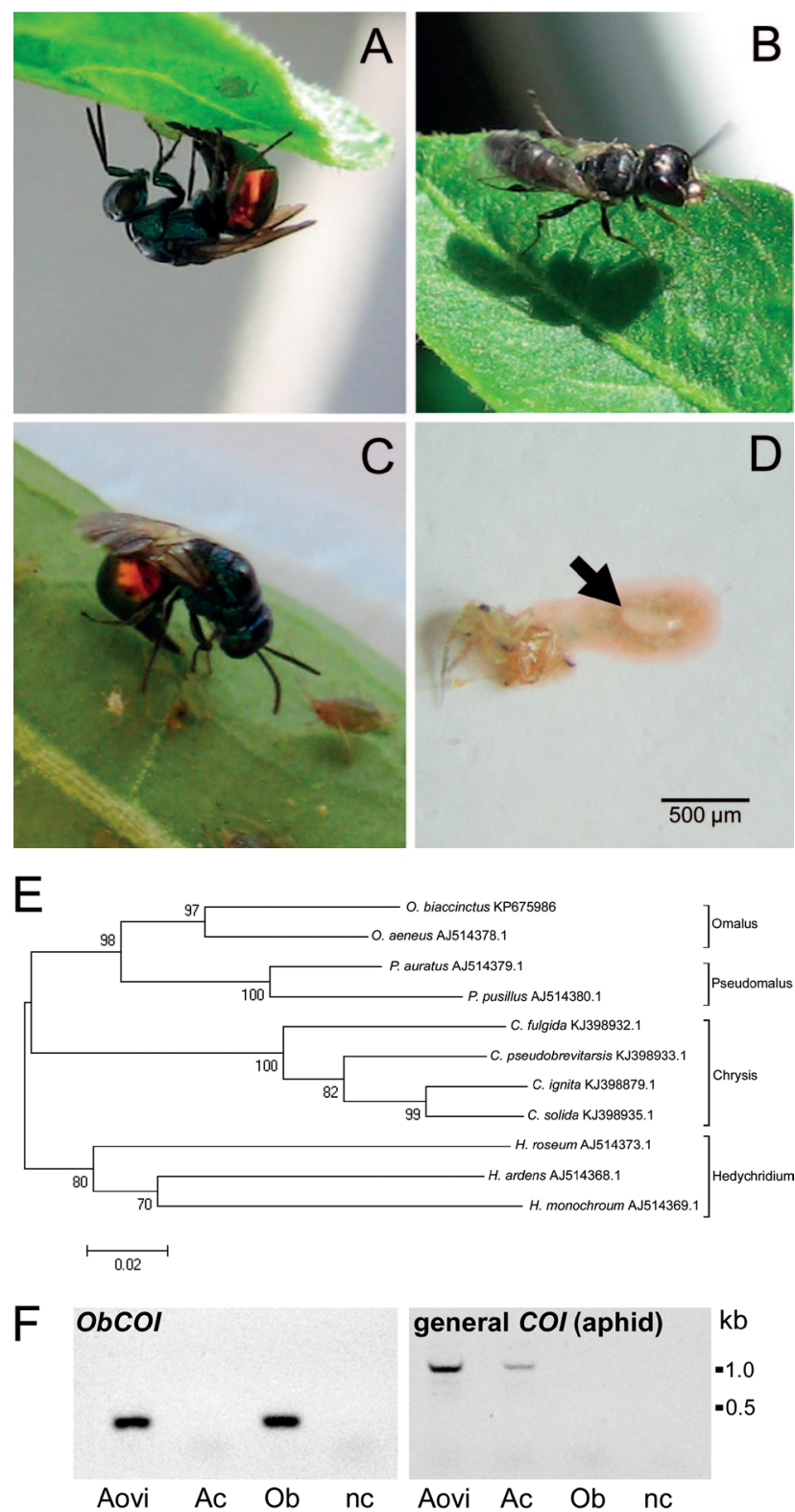

Fig. 1. O. biaccinctus ovipositing in aphids and evidence of the presence of eggs of the parasite in aphids. (A) O. biaccinctus ovipositing in aphids in the field. (B) The true host Passaloecus spp. collecting aphids from the same plant. (C) O. biaccinctus ovipositing in an aphid under controlled conditions in captivity. (D) An aphid dissected after exposure to oviposition by $O$. biaccinctus under controlled conditions; the parasitoid egg in the body contents is indicated by the arrow. (E) Phylogenetic tree based on the cytochrome oxidase I (COI) DNA sequences of different species of chrysidids, Genbank sequence ID is indicated by the identifier following each species' name. (F) Detection of the O. biaccinctus cytochrome oxidase I ( $\mathrm{ObCOI})$ gene using specific primers and a DNA quality check with general primers targeting aphid COI, respectively. Samples: Aovi - aphid after oviposition; Ac - aphid control; $\mathrm{Ob}-O$. biaccinctus; $\mathrm{nc}$ - non-template control; kb - kilobase.

displayed the oviposition behavior as described above mainly in juvenile aphids (Fig. 1C). The aphids were active and continued feeding during and after the wasp's treatment; the aphid is not paralyzed by the wasp. The aphids subject to this treatment were collected for analysis and examined individually. Wasp eggs were 
not found attached to their surface and the ventral side appeared intact. On dissection each of these aphids $(n=10)$ was found to contain an egg (Fig. 1D). The chorion of the egg was very delicate and broke at the slightest touch (which hindered further detailed analysis), indicating a typical endoparasitic egg with a thin chorion as described by Pennacchio \& Strand (2006). Such eggs were not found in aphids that were ignored by the cuckoo wasps, or in control aphids not exposed to the wasps $(n=15)$.

\section{Detection of chrysidid DNA in aphids}

To verify the presence of the parasite in aphids a fragment of the $\mathrm{COI}$ gene of $\mathrm{O}$. biaccinctus (ObCOI) was isolated (Genbank ID: KP675986) and bioinformatically analyzed. The isolated sequence was most similar (92\%) to the COI sequence of $O$. aeneus (Genbank ID: AJ514378.1). Furthermore, a phylogenetic analysis including $C O I$ sequences from other species of chrysidids revealed clustering at the genus level. In the phylogenetic tree the $O b C O I$ sequence, as expected, was adjacent to the $C O I$ sequence of its closest relative, O. aeneus (Fig. 1E). The presence of DNA from the parasite in aphids was confirmed using PCR and primers specific for $O b C O I$. It was detected in DNA samples obtained from aphids exposed to oviposition by $O$. biaccinctus, but not in those from control aphids (Fig. 1F). These results indicate that $O$. biaccinctus inserts eggs into living aphids, although the aphid itself is not a suitable host and the cuckoo wasp is known to develop in a brood cell of the host crabronid stocked with aphids.

\section{CONCLUSION}

The cuckoo wasp $O$. biaccinctus and very likely other species of chrysidids that parasitize aphid-hunting crabronids and have similar oviposition behavior apparently oviposit inside living aphids that are the prey of their host. While the crabronid host collects aphids, the parasitoid oviposits in aphids close to the host's hunting site, which might increase the probability that the host wasp will collect aphids containing chrysidid eggs. In this way the chrysidid parasitoid can clandestinely enter the nest of its crabronid host by "hitch-hiking" in the body of an aphid collected by the host to provision the brood cell. The chrysidid thus does not need to locate and penetrate a nest of the crabonid host wasp in order to lay its eggs.

\section{OUTLOOK}

Further detailed research on the oviposition strategy and physiology of cuckoo wasps in chrysidid-crabronid interactions should target (i) how the hunting crabronid host is identified and located by the chrysidid and (ii) how the development and hatching of the parasitoid egg in an aphid is physiologically controlled. In addition, (iii) the hunting behavior of the host wasp and (iv) the potential crabronid defense strategies for reducing the incidence with which it is parasitized by cuckoo wasps should be analyzed.

ACKNOWLEDGEMENTS. The author thanks O. Niehuis and C. Schmid-Egger for confirming the identity of the wasps and C.P.W. Zebitz for determination of the aphids, respectively. The valuable comments and suggestions of the reviewers are highly appreciated.

\section{REFERENCES}

Carrillo J.L. \& Caltagirone L.E. 1970: Observations on the biology Solierella peckhami, S. blaisdelli and two species of Chrysididae. - Ann. Entomol. Soc. Am. 63: 672-681.
COLLetT T.S. 2008: Insect behaviour: learning for the future. Curr. Biol. 18: 131-134.

Corbet S.A. \& Backhouse M. 1975: Aphid-hunting wasps: a field study of Passaloecus. - Ecol. Entomol. 127: 11-30.

EgGLeton P. \& Belshaw R. 1992: Insect parasitoids: an evolutionary overview. - Phil. Trans. R. Soc. Lond. (B) 337: 1-20.

FRICKE J.M. 1992: Factors influencing length and volume of cells provisioned by two Passaloecus species (Hymenoptera: Crabronidae). — Great Lakes Entomol. 25: 107-114.

Kelley S.T., Farrell B.D. \& Mitton J.M. 2000: Effects of specialization on genetic differentiation in sister species of bark beetles. - Heredity 84: 218-227.

KuRCZEWSKi F.E. 1967: Hedychridium fletcheri (Hymenoptera: Chrysididae, Elampinae), a probable parasite of Tachysphex similis (Hymenoptera: Sphecidae, Larrinae). - J. Kans. Entomol. Soc. 40: 278-284.

Larkin M.A., Blackshields G., Brown N.P., Chenna R., McGettigan P.A., McWilliam H., Valentin F., Wallace I.M., Wilm A., Lopez R., Thompson J.D., Gibson T.J. \& Higgins D.G. 2007: ClustalW and ClustalX version 2. - Bioinformatics 23: 2947-2948.

Machauer M. \& VöLKL W. 1993: Regulation of aphid populations by aphidiid wasps: does parasitoid foraging behaviour or hyperparasitism limit impact? - Oecologia 94: 339-350.

Pennacchio F. \& Strand M.R. 2006: Evolution of developmental strategies in parasitic Hymenoptera. - Annu. Rev. Entomol. 51: 233-258.

RosenHeIM J.A. 1987: Host location and exploitation by the cleptoparasitic wasp Argochrysis armilla: the role of learning (Hymenoptera: Chrysididae). - Behav. Ecol. Sociobiol. 21: 401-406.

Simon C., Frati F., Beckenbach A., Crespi B., Liu H. \& Flook P. 1994: Evolution, weighting, and phylogenetic utility of mitochondrial gene sequences and a compilation of conserved polymerase chain reaction primers. - Ann. Entomol. Soc. Am. 87: 651-701.

Strohm E., Laurien-Kehnen C. \& Bordon S. 2001: Escape from parasitism: spatial and temporal strategies of a crabronid wasp against a specialised cuckoo wasp. - Oecologia 129: 50-57.

Strohm E., Kroiss J., Herzner G., Laurien-Kehnen C., Boland W., Schreier P. \& Schmitt T. 2008: A cuckoo in wolves' clothing? Chemical mimicry in a specialized cuckoo wasp of the European beewolf (Hymenoptera, Chrysididae and Crabronidae). — Front. Zool. 5: 2.

Tamura K., Dudley J., Nei M. \& Kumar S. 2007: MEGA4: Molecular Evolutionary Genetics Analysis (MEGA) software version 4.0. - Mol. Biol. Evol. 24: 1596-1599.

van Nouhuys S. \& KaARTinen R. 2008: A parasitoid wasp uses landmarks while monitoring potential resources. - Proc. $R$. Soc. (B) 275: 377-385.

VeenendaAl R.L. 2011: Pseudomalus triangulifer, a cuckoo wasp new to the Dutch fauna (Hymenoptera: Chrysididae). - Ned. Faunist. Meded. 35: 17-20.

VeEnendaAl R.L. 2012: The biology of Holopyga generosa (Hymenoptera: Chrysididae). — Ned. Faunist. Meded. 37: 39-43.

Received January 30, 2015; revised and accepted March 20, 2015 Prepublished online May 15, 2015 